\title{
Relações de gênero no Acampamento llha Verde: discutindo o (des)empoderamento das mulheres beneficiárias do Bolsa Família
}

\author{
Gender relations in Ilha Verde Camp: discussing the (dis) empowerment of \\ women beneficiaries of welfare aid Bolsa Família \\ Relaciones de género en el Campamento Ilha Verde: discutiendo el \\ (des) empoderamiento de las mujeres beneficiarias de la asistencia social \\ Bolsa Família
}

\author{
Hareli Fernanda Garcia Cecchin ${ }^{1}$ \\ Temis Gomes Parente ${ }^{1}$
}

Recebido em 13/03/2018; revisado e aprovado em 27/05/2018 aceito em 19/06/2018

DOI: http://dx.doi.org/10.20435/inter.v0i0.1882

\begin{abstract}
Resumo: A pesquisa teve como objetivo analisar os efeitos do Programa Bolsa Família nas relações de gênero e no empoderamento das mulheres do Acampamento Ilha Verde, localizado em Babaçulândia, TO. Utilizou-se a História Oral para compreender se houve empoderamento das mulheres nas dimensões pessoal, interpessoal e coletiva, entre os quais o Programa Bolsa Família é um elemento presente nessas dimensões.
\end{abstract} Palavras-chave: gênero; empoderamento; Programa Bolsa Família.

Abstract: The purpose of this research was to analyze the effects of the "Bolsa Família" Program on gender relations and women's empowerment in Ilha Verde Camp, located in Babaçulândia, TO. The Oral History was used to understand if there was empowerment of women in the personal, interpersonal and collective dimensions, among which the 'Bolsa Familia' Program is a present element in these dimensions.

Keywords: gender; empowerment. Family Grant Program.

Resumen: El objetivo de esta investigación es analizar los efectos del programa de asistencia social "Bolsa Família" sobre las relaciones de género y el empoderamiento de las mujeres en el Campamento Ilha Verde, ubicado en Babaçulândia, TO. La Historia Oral se utilizó para comprender si hubo empoderamiento de las mujeres en las dimensiones personal, interpersonal y colectiva, entre los cuales el Programa Bolsa Familia es un elemento presente en estas dimensiones.

Palabras clave: género; empoderamiento; programa de asistencia social Bolsa Família.

\section{INTRODUÇÃO}

O Programa Bolsa Família é um benefício que compõe a política de transferência de renda do Sistema Único de Assistência Social (SUAS) e tem como foco a garantia de renda, a inclusão produtiva e o acesso aos serviços públicos. Desde a instituição do programa, em 2004, a mulher tem prioridade na titularidade do benefício por se considerar que ela é mais cuidadosa que o homem na administração dos valores recebidos, aplicando-os em prol da família, tanto a curto como a longo prazo (MOREIRA et al., 2012). Essa focalização, segundo a política de Assistência Social, também se dá como uma estratégia para fortalecer o papel da mulher na família e na comunidade (TRIERWEILER; MEDEIROS, 2015), uma vez que tem aumentado no país o número de mulheres que chefiam as suas famílias.

Uma vez que o programa possui impactos financeiros e sociais na vida de seus beneficiários, sobretudo das mulheres - que são as titulares do benefício e, em geral, as responsáveis por administrá-lo -, o Bolsa Família foi tomado como objeto de pesquisa. Buscou-se observar se este provocou transformações na situação familiar das mulheres do Acampamento Ilha Verde,

\footnotetext{
${ }^{1}$ Universidade Federal de Tocantins (UFT), Palmas, Tocantins, Brasil.
} 
no município de Babaçulândia, TO, em especial quanto às relações de gênero e ao processo de empoderamento dessas mulheres.

Gênero é aqui entendido como uma maneira de compreender as relações de poder e de estruturar os modos de perceber e organizar a vida social de homens e mulheres (SAFFIOTI, 2009). Trata-se de perceber o lugar da mulher na vida social e o reconhecimento ou não de suas individualidades. Essas relações assimétricas geram desigualdades que, somadas a outras, como as de etnia e de classe, marcam a opressão das mulheres.

Para os estudos de gênero, os papéis relacionados a 'ser homem' e 'ser mulher' são provenientes de uma construção cultural de sentidos e significados, permeados por relações de poder que persistem até os dias atuais e influenciam no modo como homens e mulheres se relacionam, determinando características, oportunidades, expectativas. Homens e mulheres têm necessidades diferentes e devem ser tratados com igualdade, por meio de políticas e estratégias tendo as diferentes demandas como referência (ROCHA; CABA, 2012)

Para Mariano e Carloto (2009), diante de políticas públicas de transferência de renda, como o Bolsa Família, é preciso retomar as antigas questões feministas sobre o lugar das mulheres na família e a sua relação com o Estado. A grande crítica das autoras ao programa é que, com a transferência de renda, são levadas em conta as necessidades das mulheres quanto à situação de pobreza, mas não se considera a situação de subordinação feminina (MARIANO; CARLOTO, 2009). Para as autoras, o programa pode contribuir para a cristalização dos papéis sociais da mulher, pois a responsabiliza, ainda que indiretamente, pelas tarefas relacionadas ao cuidado e à maternagem.

Apesar da construção social dos papéis sociais tidos como femininos, Zapata-Martelo et al. (2004) apontam um processo de mudança, denominado empoderamento, no qual as mulheres caminham em direção ao poder com o objetivo de transformar a desigualdade nas relações de gênero. $O$ empoderamento é um processo multidimensional, porque envolve o âmbito político, o econômico, o social, o cultural e outros, e implica satisfação não só no âmbito pessoal, mas também no coletivo (HORTA; CARRILLO; ZAPATA-MARTELO, 2015).

Para Zapata-Martelo et al. (2008), existem três dimensões do empoderamento: a pessoal, a das relações interpessoais e a coletiva ${ }^{2}$. Em cada dimensão do empoderamento, há fatores inibidores e fatores impulsionadores desse processo de mudança. Entre os fatores inibidores, estão a falta de controle sobre o tempo pessoal, a opressão internalizada e a falta de apoio das autoridades; e, entre os fatores impulsionadores, estão o desenvolvimento de conhecimentos e habilidades, fazer parte de um grupo e compartilhar problemas, e o reconhecimento legal, para citar alguns. Esses fatores serão explorados na análise das entrevistas.

\section{PERCURSO METODOLOGICO: COMPREENDENDO O BOLSA FAMÍLIA POR MEIO DAS}

\section{NARRATIVAS DAS MULHERES}

Este trabalho foi realizado a partir de uma pesquisa qualitativa com análise indutiva, uma vez que se focalizam as experiências das mulheres de um local específico, o Acampamento llha Verde, no município de Babaçulândia, TO. Foram observadas as três dimensões do empodera-

Algumas ideias sobre essa temática foram apresentadas por Cecchin e Parente em "Gênero, empoderamento resistências: discutindo o cotidiano das mulheres do Acampamento Ilha Verde-TO", no Seminário Internacional Fazendo Gênero 11 \& $13^{\text {th }}$ Women's Worlds Congress (anais eletrônicos), Florianópolis, 2017. mento (pessoal, interpessoal e coletiva) proposto por Zapata-Martelo et al. (2008) e sua relação com o Programa Bolsa Família. A partir da análise das dimensões pessoal, interpessoal e coletiva nas narrativas das mulheres pesquisadas, observou-se o processo de empoderamento naquela comunidade, principalmente quanto à administração do benefício e à participação das mulheres nos programas complementares ${ }^{3}$. Foram entrevistadas sete mulheres: cinco delas beneficiárias do Programa Bolsa Família, uma não beneficiária e a líder do Acampamento llha Verde. Esse acampamento fica na zona rural do município de Babaçulândia, TO, e foi organizado por famílias desse município e de localidades vizinhas, que não foram indenizadas durante a construção da Hidrelétrica de Estreito. O local foi escolhido devido a suas peculiaridades, tais como: o conflito quanto à posse da terra, a organização da comunidade em relação ao espaço físico e ao modo de subsistência, entre outros. As questões que esse local apresenta são significativas e relevantes para a pesquisa, uma vez que algumas pesquisas publicadas pelo Ministério do Desenvolvimento Social (MDS) (BRASIL, 2014b) demonstram que o acesso ao benefício do Programa Bolsa Família e a inserção de comunidades tradicionais e/ou rurais na política de assistência social ocorre de forma muito diversa das demais, apresentando diferenças de grupos urbanos, por exemplo.

O critério utilizado para escolha das mulheres a serem entrevistadas foi residir no Acampamento Ilha Verde, ser preferencialmente beneficiária do Programa Bolsa Família e ser casada ou residir com um companheiro, de modo que as relações de gênero pudessem ser observadas. A fase de recrutamento das participantes incluiu a confirmação do interesse em participar, verificação de elegibilidade e dos dados de identificação e a assinatura do Termo de Consentimento Livre e Esclarecido (TCLE). Os depoimentos das mulheres foram obtidos individualmente, na casa das entrevistadas em junho de 2015.

Como procedimento metodológico, foi utilizada a História Oral, que trabalha com a vida diária e com a cultura material de pessoas e grupos (PORTELLI, 1997), daí a importância de se trabalhar com as fontes orais na comunidade llha Verde. A História Oral não visa a dados numéricos, mas o contato direto com os sujeitos via história narrada. A história é representada pela experiência pessoal, permeada por sentidos e significados tanto individuais como da vida coletiva (SILVA; BARROS, 2010), em que os narradores articulam memória, avaliação e relatos em diálogos com entrevistadoras/es que estão tentando ressignificar uma estrutura mais ampla (PORTELLI, 2010) - neste trabalho, a relação de (des)empoderamento das mulheres com o Bolsa Família.

Por meio da entrevista, é feito o registro da experiência (FREITAS, 2003) e das vivências dos sujeitos (FERREIRA; GROSSI, 2002). Nesta pesquisa, as entrevistas foram posteriormente transcritas e analisadas sob os referenciais teóricos de gênero e empoderamento. Ao longo do trabalho, alguns trechos das entrevistas são explicitados no texto e se utilizam os nomes reais das mulheres entrevistadas, procedimento que foi autorizado pelas participantes da pesquisa no TCLE.

As entrevistas realizadas nesta pesquisa seguiram um roteiro prévio, organizado em perguntas abertas e não diretivas, de modo a não induzir a uma resposta (THOMPSON, 2002). As perguntas foram elaboradas pelas pesquisadoras, a partir de outras experiências de pesquisa com mulheres de reassentamentos rurais (PARENTE; GUERRERO, 2011; PARENTE; JUSTINO, 2013; PARENTE, 2015) e do referencial teórico adotado. O roteiro não foi usado de modo fixo ou estável, mas apenas para orientar as entrevistas. As perguntas foram apresentadas na ordem em que 0

Os programas complementares se constituem na oferta de cursos profissionalizantes e de geração de renda acompanhamento psicossocial, buscando o desenvolvimento dos beneficiários do Programa Bolsa Família de modo que consigam superar a situação de vulnerabilidade e pobreza em que se encontram. 
discurso permitiu, e não na ordem em que apareciam no roteiro, mantendo-se um diálogo fluido, de acordo com as orientaç̃̃es de Portelli (2001), Thompson (2002) e Alberti (2005).

Os principais questionamentos estavam voltados para o histórico da entrevistada no Acampamento llha Verde, a relação dela e da família com o benefício do Programa Bolsa Família, condicionalidades do Programa, a participação nos demais serviços e programas do SUAS, questões pessoais e familiares (idade, nível de escolaridade, quantidade de filhos), relação com o companheiro e demais membros da família e da comunidade, e expectativas em relação ao futuro.

Durante algumas entrevistas registrou-se a presença do companheiro das mulheres. Em alguns momentos, esses homens também participaram da narrativa, seja complementando a fala da mulher, fazendo um comentário, expressões faciais, entre outros, o que demonstra o poder e influência da memória coletiva dessa metodologia.

Como procedimento de análise dos dados coletados, utilizou-se a triangulação de métodos (BRISOLA; MARCONDES, 2011), com a criação e utilização de categorias após a transcrição das entrevistas. Algumas categorias foram extraídas do referencial teórico de Zapata-Martelo et al. (2008) que trata das três dimensões do empoderamento (pessoal, inter-pessoal e coletivo) e os fatores que podem inibir ou impulsionar esse empoderamento. Outras categorias foram elaboradas com base nos objetivos e hipóteses de pesquisa do estudo.

Também se utilizou como procedimento de pesquisa o acesso a dados secundários, como o CADSUAS e o site do Fórum Nacional dos Trabalhadores do SUAS (FNSUAS), para obter informações sobre a participação das mulheres nas instâncias de controle social (como o Conselho Municipal de Assistência Social) e organizações de usuários do SUAS.

Esta pesquisa busca contribuir para o debate interdisciplinar de gênero, vulnerabilidade e empoderamento, bem como para o aprimoramento das políticas públicas, em especial a de Assistência Social. Os resultados visam subsidiar novas práticas aos serviços socioassistenciais que permitam a inclusão, o desenvolvimento da autonomia e o empoderamento das mulheres beneficiárias, bem como ações para o aperfeiçoamento da gestão do acompanhamento das beneficiárias do programa.

\section{TRANSFERÊNCIA DE RENDA E DESENVOLVIMENTO DA AUTONOMIA: QUAIS}

\section{ESPAÇOS SÃO OFERECIDOS NO PROGRAMA BOLSA FAMÍLIA?}

A partir de 2005, o governo federal recomendou que os beneficiários do Bolsa Família fossem acompanhados localmente por meio do Serviço de Proteção e Atendimento Integral à Família (PAIF), sob coordenação do Centro de Referência de Assistência Social (CRAS) de cada município. A estratégia buscava associar a segurança de renda (valor monetário) ao "desenvolvimento da autonomia" (BRASIL, 2009, p. 7).

Para que a transferência de renda fomentasse a autonomia das famílias, o governo lançou orientações com sugestões de temas a serem abordados pelo PAIF, entre esses o Direito das Mulheres. Ainda que o documento não mencione o termo gênero, sugere temas que tangenciam essa categoria teórica:

Direito das Mulheres: promover a reflexão sobre $o$ isolamento social das mulheres, a feminização da pobreza, a violência contra mulheres, a sobrecarga das mulheres na divisão das responsabilidades familiares etc. (BRASIL, 2012, p. 29).

Nos dados coletados nas entrevistas com as mulheres do Acampamento llha Verde, não foi registrada nenhuma participação delas em discussões sobre gênero por meio do PAIF, como preconiza a política pública de Assistência Social (BRASIL, 2012). Desconhecer os seus direitos enquanto mulheres impede que elas possam exercê-los e/ou exigi-los, fazendo com que não lutem por melhores condições de vida.

Além da transferência de renda, o Programa Bolsa Família também prevê a permanência de crianças e adolescentes na escola, a segurança alimentar e a participação de seus beneficiários em cursos profissionalizantes e de geração de renda. Este último visa "estimular a emancipação sustentada das famílias que vivem em situação de pobreza e extrema pobreza" (BRASIL, 2004, art. 4).

Durante a pesquisa realizada no Acampamento Ilha Verde, a mulheres relataram, nas entrevistas, não terem participado de nenhum curso oferecido pela política de Assistência Social. Esses cursos, se tivessem sido oferecidos, poderiam auxiliar no aperfeiçoamento da atividade de pesca, horticultura e de comercialização de produtos na feira, e de organização do negócio como um todo. Os cursos pontuais oferecidos às mulheres pelo Serviço Nacional de Aprendizagem Industrial (Senai) e pelo Serviço Nacional de Aprendizagem Rural (Senar) não contribuíram para o seu processo de capacitação, pois o que aprenderam ali não está sendo colocado em prática.

Para desenvolver a autonomia e a cidadania dos beneficiários do programa, orientou-se que estes pudessem, em cada município, acompanhar e fiscalizar a operacionalização do programa, uma vez que é executado com recursos públicos (CONSELHO NACIONAL DE ASSISTÊNCIA SOCIAL [CNAS], 2014). Esse acompanhamento se daria via Conselho de Assistência Social (tanto no nível municipal como estadual), que funcionaria também como instância de controle social do Programa Bolsa Família. Na pesquisa realizada em dados secundários como o CADSUAS, não se registrou a presença de nenhuma das entrevistadas do Acampamento llha Verde nessas instâncias de participação, o que limita a voz dessas mulheres. Nenhuma das mulheres entrevistadas relatou participar do Conselho Municipal de Assistência Social de Babaçulândia, TO.

Tendo em vista essa relação do Programa Bolsa Família com as mulheres do Ilha Verde, a pesquisa considerou não só a aplicação e a administração dos recursos do programa, mas também as relações familiares e comunitárias estabelecidas, identificando o processo de (des) empoderamento feminino. Esse processo será descrito mais adiante. No entanto é preciso compreender o contexto social, histórico e demográfico em que essas beneficiárias do Bolsa Família se encontram.

\section{BABAÇULÂNDIA, TO, O ACAMPAMENTO ILHA VERDE E A HIDRELÉTRICA DE} ESTREITO - FIOS QUE SE ENTRELAÇAM

Babaçulândia é um município do extremo norte do estado do Tocantins, na Região Norte do país, que se formou como povoado em 1926, a partir da extração do coco-babaçu ${ }^{4}$ e, posteriormente, a agricultura e a pecuária (INSTITUTO BRASILEIRO DE GEOGRAFIA E ESTATÍSTICA [IBGE], 2010). Em meados dos anos 2000, Babaçulândia e os municípios da região tiveram sua dinâmica modificada devido à construção da Usina Hidrelétrica de Estreito (UHE), no rio Tocantins. Babaçulândia foi o município mais afetado, principalmente por conta do alagamento da Ilha de São José, o que gerou muitos protestos pela população (SILVA JÚNIOR, 2014).

Na região é abundante o coco-babaçu, que é coletado e quebrado pelas mulheres para a comercialização da amêndoa do fruto, utilizada para a produção de óleo. Essa atividade extrativista compõe a renda de muitas famílias. Devido a conflitos na região, na década de 1980 as mulheres se organizaram e fundaram o Movimento Interestadual das Quebradeiras de Coco-Babaçu (MIQCB). Para mais detalhes, ler Pizzio e Cecchin (2015). 
Diversos movimentos sociais, entre eles o Movimento dos Atingidos por Barragens (MAB) se organizaram para marcar sua posição contrária à construção da barragem. Devido à não indenização de todas as famílias atingidas, por parte do Consórcio Estreito Energia (Ceste), empresa que construiu a hidrelétrica, algumas se uniram e ocuparam uma terra pertencente ao consórcio na margem do rio Tocantins.

Foi desse modo que surgiu o Acampamento Ilha Verde, uma comunidade formada por 37 famílias compostas por quatro a dez membros. Cada família ocupa um pequeno lote de terra, onde vive e cultiva algumas frutas, hortaliças e pequenos animais, como galinhas. O grupo, cujas pessoas se declaram membros do $\mathrm{MAB}$, reivindica uma indenização e afirma que não desocupará a área até que a questão seja resolvida (CECCHIN; PARENTE, 2016).

A comunidade do Ilha Verde está organizada de modo diferente dos tradicionais acampamentos do Movimento dos Trabalhadores Rurais Sem Terra (MST), onde em geral se constroem moradias provisórias às margens de rodovias e estradas ou em fazendas (FIGUEIREDO; PINTO, 2014), até a conquista de uma terra. No llha Verde, as casas são feitas de madeira e cobertas de palha no local onde a comunidade deseja a posse da terra, à beira do rio Tocantins (CECCHIN PARENTE, 2016)

O sustento das famílias se dá pelo benefício do Programa Bolsa Família e do Programa Seguro Defeso ${ }^{6}$ (no caso daqueles que têm registro de pescador ou pescadora profissional), além da venda de produtos na feira da cidade. A feira acontece na área urbana de Babaçulândia duas vezes por semana (sexta-feira e sábado) no período matutino. As mulheres do llha Verde trabalham de domingo a quinta-feira na produção e empacotamento das hortaliças, peixes e demais produtos alimentícios que serão vendidos (CECCHIN; PARENTE, 2016). O poder público municipal concede transporte gratuito para levar a comunidade e seus produtos para a cidade, facilitando a comercialização dos gêneros alimentícios produzidos. Logo após a feira, essa população retorna para o acampamento com o mesmo transporte. Na maior parte dos casos, a renda das famílias não ultrapassa o valor de um salário-mínino.

Segundo Parente (2012), as mulheres são em geral as mais afetadas pelos projetos de grande porte (construção de hidrovias, ferrovias e hidrelétricas) devido aos laços de amizade que elas estabelecem com os demais membros da comunidade. Contraditoriamente, são elas que têm menor participação nos debates públicos para a implantação desses projetos e que recebem um valor de indenização menor. Citando um documento elaborado pela Investco S.A. ${ }^{7}$, em texto de Araújo (2003), explica que a indenização é desigual entre homens e mulheres, pois se considera que os homens têm maior força de trabalho, caracterizando, portanto, as relações de gênero.

Esses grandes empreendimentos são fomentados com o discurso de que levam desenvolvimento para uma região (PARENTE, 2007). Apesar disso, o município de Babaçulândia continua marcado por desigualdades sociais. Os dados do governo federal apontam que, em 2017, 36\% da

O Movimento dos Atingidos por Barragens (MAB) foi criado em 1988, a partir da unificação das demandas de pequenos agricultores que, em diferentes partes do país, perderam suas propriedades ou parte delas devido ao projeto de expansão assumido pelo setor elétrico brasileiro (FRAGA, 2013).

O seguro-defeso é um beneficio temporário concedido aos pescadores artesanais durante o periodo em que os peixes se reproduzem (piracema), epoca na qual a pesca e proibida, contribuindo para a preservação de várias espécies do ecossistema brasileiro. Para mais detalhes, consultar Campos e Chaves (2014).

A Investco S.A. é a empresa que é titular exclusiva dos ativos que compõem a Usina Hidréletrica Luís Eduardo Magalhães (UHE Lajeado), localizada no rio Tocantis, nos munícipios de Lajeado e Miracema do Tocantins, estado de Tocantins. população de Babaçulândia ${ }^{8}$ vivia em situação de pobreza, com renda mensal de até $R \$ 170,00$ por pessoa (BRASIL, 2017).

As mulheres do Acampamento Ilha Verde fazem parte desse contexto, pois as entrevistadas possuíam idade entre 24 e 48 anos, grau de escolaridade entre o 50 ano do Ensino Fundamenta até o Ensino Médio completo. Elas possuíam de dois a oito filhos - em alguns casos, além dos filhos biológicos, cuidavam de sobrinhos e netos.

Localizado na zona rural, o Acampamento llha Verde apresenta condições de habitação precárias, sem esgotamento sanitário nem água encanada. A ausência de infraestrutura é explicada pelas/os moradoras/es com o argumento de que ainda se encontram sob a forma de acampamento, o que não permite a construção de moradias definitivas até que a posse da terra seja concedida às famílias.

Para compreender a administração do benefício do Programa Bolsa Família no Acampamento Ilha Verde, é preciso considerar a renda familiar como um todo, uma vez que todas as mulhere entrevistadas vendem produtos na feira, obtendo um recurso a mais. Os relatos demonstram que as famílias não separam essas duas fontes de recurso financeiro. No entanto, como o benefício tem uma regularidade, pois em geral vem sempre na mesma quantidade e no mesmo dia todos os meses, é mais usado para pagar contas parceladas, como pode ser observado no depoimento de Aparecida:

E, eu compro roupa para os meninos, eu compro remédio, muitas vezes eu compro umas coisas fiado, sabe. Ai quando chega aquela data daquele dinheirinho ali, eu já tiro e pago aquela conta, pago dia de servico pra ajudar na horta tira do Bolsa Família, tira da horta, já pago diária pra dia ajudar. [.] Tenho um 'freezer' que eu comprei pra fazer ge lo pra him ja pago diaria pra me ajudar. [...] Tenho um Jreezer que eu comprei pra fazer gelo pra mim . L dos peixes e pago o 'freezer'.

No caso das entrevistadas, percebeu-se que houve um maior poder de decisão dentro do grupo doméstico, pois em geral a mulher opina sobre o que vai ser comprado com o benefício com a renda familiar como um todo. Todas as entrevistadas mencionaram essa questão. Citamos aqui o relato de Aparecida, ela conta que, apesar de o esposo ir junto às compras, é ela quem decide os produtos que serão adquiridos.

Tem vez que eu vou mais com Lúcia, outras vou com Luiz [esposo], às vezes eu vou só. Faço as compras e venho embora. [...] nós só faz pensar, 'não, vamos comprar isso', aí nós vai lá e compra. Aí nós deixa o dinheiro, não gasta, nós deixa o dinheiro pra aquele tipo de coisa, aí nós vamos lá e compra. Igual o motorzinho de luz. Nós mexemos com a horta, nós precisamos do motorzinho de luz. Ai nós fomos lá, comprei o motor de luz, depois eu arrumei outro dinheiro, comprei a bomba e os cano pra molhar o canteiro, pra ficar mais melhor pra gente dar conta da horta.

Nesse relato, fica claro que Aparecida usa a renda da família para comprar instrumentos que reduzam o tempo gasto com a horta, uma de suas obrigações. Para muitas feministas, as obrigações domésticas constituem um mecanismo de domesticação da mulher, que restringe e limita suas possibilidades de atuação, sobretudo no âmbito da esfera pública (HORTA; CARRILLO;

Considerando que em 2017 a população estimada de Babaçulândia era de 10.752 habitantes, sendo que 21,3\% da população em situação de pobreza vivia na área rural, contra 7,4\% na área urbana, segundo o IBGE. Disponive em: https://cidades.ibge.gov.br/xtras/perfil.php?lang=\&codmun=170300\&search=tocantins|babaculandia. Acesso em: 16 jan. 2018. 
ZAPATA-MARTELO, 2015). Com a aquisição de produtos que diminuam o tempo gasto com a horta, Aparecida consegue tempo para se dedicar a outras atividades que não aquelas relacionadas ao papel de responsável pelo lar.

Contudo percebeu-se que as mulheres do llha Verde também estão imersas em relações de gênero que provocam desempoderamento. A seção a seguir discute as contradições e instabilidades em torno do cotidiano dessas mulheres a partir das três dimensões de empoderamento propostas por Zapata-Martelo et al. (2008): pessoal, das relações interpessoais e coletiva.

\section{FATORES INIBIDORES DO EMPODERAMENTO NA DIMENSÃO PESSOAL}

No llha Verde foram encontrados diversos fatores inibidores do empoderamento, como a relação com o companheiro, que tende a ser de dependência. No momento das entrevistas, as mulheres procuravam "incluir" o companheiro na conversa. A influência masculina não se dá apenas pelo companheiro, mas também por pessoas externas, como vizinhos e familiares, situação também encontrada nos estudos de Zapata-Martelo et al. (2008). Em seu relato, Aparecida comenta que deixou de realizar a atividade de mergulho durante a pesca porque seus irmãos disseram que era perigoso

No tempo que era o rio, que nós botava espiel, o peixe enganchava o espiel lá no fundo, nós ia mergulhava e trava o peixe de dentro dos paus, das moitas de sará. Eu e meus irmãos, nós não tinha medo naquele tempo de nada ne?!. [...] Desde pequena que eu era desse jeito. E hoje hão vou mais hoje porque virou esse lago. [... Mas eu não fui mais. Não é porque eu vi nada assim nesse dia, é porque os meus irmãos disse não pra mim está fazendo mais isso porque pode ter outro bicho, né?! Aí não fui mais [...].

Além do machismo existente na relação com familiares e vizinhos, outro fator que inibe empoderamento é o analfabetismo ou a baixa escolaridade. Alcione relata que tem muita dificuldade em realizar operações bancárias:

Ah, minha filha, eu tinha tanta vontade de ter terminado os meus estudos, hoje eu sou arrependida de não te terminado. [...] É, por exemplo, mexer com banco, eu tenho um pouco de dificuldade, sabe? Isso aí eu já sinto dificuldade. E tem várias coisas assim que eu tenho dificuldade. A gente tem que seguir informacão, muitas coisas tem que pedir informaça dificuldade. A gente ten que segur informac̃a, mutas coisas tem que pedir informação. Mas eu vejo que se eu tivesse estudado, eu sabia, né? Não era toda coisa que eu tinha que
pedir informaçẫo.

A baixa escolaridade traz consigo a dificuldade em lidar com os recursos obtidos com a renda dos produtos comercializados na feira e com o benefício do Programa Bolsa Família. A despeito das duas fontes de recursos financeiros, as mulheres do Acampamento llha Verde trabalham para a sobrevivência de si mesmas e do grupo familiar. A renda é escassa e não permite o investimento em outros tipos de negócios, que poderiam contribuir para o seu empoderamento. O relato de Shirlene ilustra isso:

Sempre nós fala que o dinheiro é dos meninos, né? [...] É, porque sempre o que eu entendo sempre assim que vem mais é por causa dos meninos. Ai no caso eu gasto mais é com eles. A não ser com eles eu compro assim, coisa de comida.

As mulheres narram que, após o pagamento de todas as despesas da família, se sobrar algum recurso financeiro, elas o utilizam para adquirir de modo parcelado produtos voltados para a família, como relata Janete:
Da Bolsa Família eu já comprei uma televisão. [...] Eu comprei um guarda-roupa também a cômoda pra Amanda [filha].

Isso mostra que elas tendem a investir mais nos gastos familiares do que com elas mesmas. 0 modo como direcionam a renda reafirma os papéis de gênero, uma vez que fazem aquisição de utensílios para a casa, a partir do papel de dona de casa e o de boa mãe internalizados ${ }^{9}$. No entanto esses bens não conseguem mudar a vida de suas famílias ou trazer novas perspectivas para elas ou para os membros do grupo familiar, ou mesmo para mudar a realidade da comunidade, pois são bens domésticos e de consumo, não ampliando os recursos econômicos e pessoais das mulheres.

Na dimensão pessoal, foram identificados todos os fatores inibidores propostos por Zapata-Martelo et al. (2008). O machismo está presente não só na relação com os esposos, mas também na relação com outros familiares. A sobrecarga com os trabalhos domésticos impede as mulheres de continuarem seus estudos e desenvolverem novas habilidades. A única atividade realizada fora de casa, como a venda de produtos na feira, está ligada à subsistência da família. A renda proveniente da comercialização desses produtos e do Programa Bolsa Família é baixa e consegue manter apenas os gastos com alimentação e vestuário, impedindo essas mulheres de investirem em si.

\section{O DESEMPODERAMENTO NA DIMENSÃO INTERPESSOAL}

Essa dimensão está relacionada à convivência da mulher com os membros do grupo familiar (esposos e filhos) e da comunidade em geral, e a capacidade de negociação (ZAPATA-MARTELO et al., 2008). No Acampamento Ilha Verde, muitas mulheres contam com o apoio das filhas e de irmãs devido à falta de apoio dos companheiros e outros membros da família. Para que uma mulher possa trabalhar, outra tem que sacrificar seu tempo cuidando das crianças. Isso impacta negativamente no tempo das mulheres, ocasionando uma sobrecarga de serviços e limitando as possibilidades de inserção no mercado de trabalho (FREITAS, 2011).

Os estereótipos de gênero são um fator inibidor do empoderamento. Tais estereótipos são externalizados no relato do senhor Luís, companheiro da entrevistada Aparecida. Ele demonstra sua cobrança para que a esposa exerça os papéis de pescadora e dona de casa, tentando conciliar os dois:

É porque, numa parte, é bom porque ajuda, agora outra, assim que, ela se for mesmo na gestão dela ela quer ficar mais no rio do que na casa. E ai a gente tem que, vamos dizer, levar uma base assim que não atrapalhe nem um e nem outro, né?! Nem tanto o trabalho da pequenas, ai para nós ir lá para longe, e ai tem que ficar. Às vezes tem que ficar na crianças que dá assistência na casa também. Aí não pode diretamente tá indo todo dia por conta disso.

Ainda que esse senhor relate que a atividade pesqueira da esposa ajude no orçamento amiliar, percebe-se que, no Acampamento llha Verde, a pesca é imprescindível para as despesas da casa, como relata Aparecida ao explicar sobre o motivo que a mantém no local.

Mas eu falei pra eles que enquanto eles não pagar nós fica na beira do lago, vou ficar pescando mexendo com horta que e dá ai que tô tirando o sustento da casa. Comprando coisa para o

Para uma melhor compreensão sobre a internalização de uma boa mãe, ler Calafate e Parente (2014). 
menino, material do colégio e tudo, roupa e tudo de comer; é da horta e da minha pescaria, e eles nunca pagaram pescador. E aí é por isso que estou aqui na beira do lago, acampada.

Embora a pesca seja uma atividade produtiva e importante para a renda familiar, o senhor Luís afirma que a esposa precisa ficar em casa cuidando dos filhos. Nesse ponto, percebem-se as contradições presentes no lugar do feminino na sociedade, pois ainda que as mulheres executem uma dupla jornada de trabalho ao cuidar da casa, dos filhos e se envolver nas atividades para o sustento da família, as grandes empresas oferecem uma indenização menor às mulheres, como no caso da Investco.

No trecho da narrativa do senhor Luís, percebe-se a influência das relações de gênero, sobretudo do papel feminino nos serviços domésticos e no desejo do narrador de que sua esposa, por meio do discurso, passe a imagem de boa dona de casa. Para Portelli (2001, p. 12), o discurso oral é marcado pelo "empenho pela exatidão, reparos à conversa, correções e um esforço pessoal na composição de uma performance", numa busca por um discurso socialmente aceito.

\section{O DESEMPODERAMENTO NA DIMENSÃO COLETIVA}

A dimensão coletiva está relacionada com as redes de organizações, o reconhecimento por parte de outras pessoas e a participação política (ZAPATA-MARTELO et al., 2008). Uma pesquisa no Sistema de Cadastro do SUAS (CADSUAS) $)^{10}$ confirmou que não existe a participação de nenhuma beneficiária do Programa Bolsa Família do Acampamento Ilha Verde no Conselho Municipal de Assistência Social (CMAS) de Babaçulândia (BRASIL, 2014a).

Também não foi registrada a existência de Fórum Municipal ou Fórum Estadual de Usuários do SUAS, informação que foi consultada no site do Fórum Nacional de Usuários do SUAS ${ }^{11}$. O Fórum de Usuários se constitui em um outro espaço de organização coletiva para os beneficiários do Programa Bolsa Família. Para as mulheres, sobretudo as que se encontram em uma situação financeira mais difícil, é um desafio conciliar trabalho remunerado e participação social (BRASIL, 2014b), uma vez que as responsabilidades familiares ocupam quase todo o seu tempo.

Outro fator que inibe o empoderamento coletivo, sobretudo em relação à atividade produtiva de comercialização dos produtos, é a falta de apoio técnico e capacitação administrativa. Conforme apontam Zapata-Martelo et al. (2008), a falta de conhecimentos sobre o manejo financeiro e administrativo faz com que fracassem os pequenos negócios iniciados pelas mulheres.

Nas entrevistas, percebeu-se o manejo inadequado dos recursos financeiros no âmbito individual por parte das mulheres, o que dificulta a organização coletiva - que depende de investimento, de tempo, energia e recursos dos membros para existir. Para que haja empoderamento, é preciso que as mulheres se organizem, ajudem umas às outras e levem demandas para o Estado (CELARIÉ, 2003). No relato de Alcione, ela conta que se uniu a outras mulheres para lutar pela assistência de saúde:

Até que sobre isso a gente lutou. Juntou eu e a Shirlene ali, e a Euglênia, a gente foi na Secretaria de Saúde e pediu um agente de saúde para cá. [...] Demorou, mas graça a Deus ele vem todo mês. Inclusive ontem ele veio aqui.

\footnotetext{
Os dados básicos de cada conselho municipal são de livre acesso, podendo qualquer cidadão, sem o uso de senha, ter acesso a eles por meio do CADSUAS, no endereço eletrônico: http://aplicacoes.mds.gov.br/cadsuas/ recarregarTipoEntidade.html. Acesso em: 16 jan. 2018.
}

${ }^{11}$ Informações disponíveis em: http://forumusuariosuas.org. Acesso em: 6 dez. 2017.
No entanto as mulheres do acampamento não conseguiram ter mobilidade e estabelecer uma presença pública no município onde residem. A comunidade do llha Verde não conseguiu desenvolver uma identidade coletiva e unir esforços para exercer pressão política sobre as autoridades.

Nas entrevistas, as mulheres identificam apenas as suas demandas individuais, sobretudo aquelas ligadas à sobrevivência, sem que se identifiquem necessidades coletivas. Elas reclamam da falta de infraestrutura no acampamento ${ }^{12}$, da distância em relação à cidade e da falta de transporte. Além da incerteza quanto a permanecer na terra, como pode ser observado no relato de Alcione:

Ah, minha filha, no meu futuro, se eles organizassem a nossa situação nos desse casa, uma

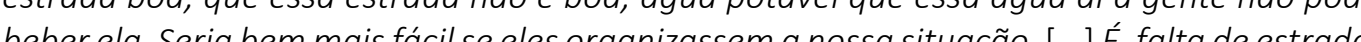

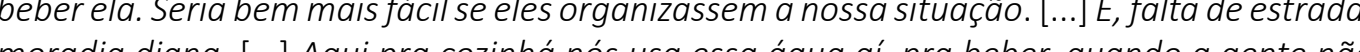
moradia digna. [...] Aqui pra cozinhá nós usa essa água al, pra beber, quando a gente não traz da rua, a gente tem que atravessar esse rio, esse lago, para ir apanhar num ribeirãozinho que tem a água. Eu sou difícil trazer da rua, porque até porque eu me acho em dificuldade porque o transporte que nós temos é essa moto, pra trazer um bujão de água fica dispendioso.

A falta de moradia digna, transporte adequado, energia elétrica, água potável, além da incerteza quanto à posse da terra, da baixa escolaridade, insuficiência de renda e falta de apoio dos companheiros dificultam o processo de empoderamento das mulheres. No entanto percebe-se que a maioria delas identifica as demandas relacionadas às questões de infraestrutura do acampamento, talvez porque este já tenha se tornado um discurso coletivo na localidade.

$\mathrm{Na}$ dimensão coletiva, identificaram-se diversos entraves ao empoderamento. As mulheres não conseguem se organizar coletivamente, tanto para pressionar as autoridades como para construir coletividades (associação, cooperativa), o que é considerado por Zapata-Martelo et al. (2008) um fator inibidor do empoderamento.

\section{CONSIDERAÇÕES FINAIS}

A pesquisa buscou investigar se houve empoderamento das mulheres nas dimensões pessoal, interpessoal e coletiva, e quais as contribuições do Programa Bolsa Família no cotidiano das mulheres do Acampamento Ilha Verde. Nessa localidade, as mulheres lidam com duas fontes monetárias - o benefício do programa e a renda da venda de produtos na feira. As mulheres entrevistadas relataram que o benefício tem sido importante na vida delas, pois faz parte da renda familiar, permitindo a aquisição de bens para a família e, em alguns casos, para a aquisição de ferramentas que diminuem o tempo gasto com o cultivo de hortaliças.

$\mathrm{Na}$ dimensão pessoal, foram observados diversos fatores que inibem o empoderamento, tais como a baixa escolaridade das mulheres, a dificuldade de investir em outros tipos de negó cio, a tendência a usar os recursos para aquisição de utensílios para a casa, a partir do papel de dona de casa e de boa mãe internalizados. Soma-se a isso a ausência de discussões sobre gênero por parte do poder público, o que contribui para que as mulheres desconheçam seus direitos. Percebe-se uma introjeção e subjulgamento das mulheres às representações machistas. Muitas não se sentem competentes para realizar outras atividades que fujam do estereótipo de gênero estabelecido socialmente.

${ }^{2}$ Ainda que a falta de infraestrutura esteja vinculada ao processo de luta pela posse da terra. 
A ausência de cursos relacionados à capacitação profissional e do acompanhamento via PAIF, citados ao longo do artigo, impede que a transferência de renda seja complementada com ações que fomentem a autonomia e o desenvolvimento local. Os cursos não conseguiram gerar uma mudança nas atividades econômicas (aumento ou incremento da produção e venda de hortaliças e de peixes) ou um aumento dos recursos financeiros obtidos com a venda dos produtos na feira.

Na dimensão interpessoal, observou-se que, para uma mulher poder trabalhar, outra tem de sacrificar seu tempo cuidando das crianças ou da casa, o que inibe o empoderamento. Os estereótipos de gênero, a organização social da comunidade e suas estratificações patriarcais contribuem para que as mulheres não problematizem sobre a responsabilidade dos trabalhos domésticos com seus companheiros, e que se mantenham subordinadas a eles por meio do controle e do medo. Percebe-se ainda uma ausência dos agentes públicos na comunidade.

Na dimensão coletiva, constatou-se uma ausência de participação nas arenas decisórias destinadas aos beneficiários do Programa Bolsa Família, como o Conselho Municipal de Assistência Social ou o Fórum de Usuários do SUAS, mencionados ao longo do artigo. A falta de apoio técnico e de capacitação administrativa tem inibido o empoderamento dessas mulheres, tanto no nível individual como coletivo, pois elas não possuem uma associação que lhes permita desenvolver um plano de negócio ou um planejamento do que vão levar para vender (todas elas levam produtos semelhantes para a feira). A ausência de organização coletiva impede-as de unir esforços para exercer pressão política sobre as autoridades, diminuindo sua capacidade de negociação. Detectou-se também que no acampamento há uma ausência de formação política e, portanto, de possibilidades de formação de novas lideranças, o que compromete a continuidade do grupo.

A partir das entrevistas, evidenciam-se os limites e as possibilidades nas relações de gênero no cotidiano das mulheres do Acampamento Ilha Verde, entre os quais o Programa Bolsa Família é um dos elementos presente nessa relação. Acredita-se que seja um desafio para o Programa Bolsa Família implementar um de seus objetivos, preconizados no Decreto n. 5.209, de 17 de dezembro de 2004, que é o de "estimular a emancipação sustentada das famílias que vivem em situação de pobreza e extrema pobreza" (BRASIL, 2004).

Destaca-se que o Programa Bolsa Família não é o único que poderá empoderar as mulheres e reduzir a pobreza das famílias. Ele pode contribuir para que as mulheres se sintam capazes de decidir e realizar determinadas ações, tomando o poder para si. É importante destacar que o desenvolvimento local se dá por meio de um conjunto de fatores relacionados ao contexto e ao espaço onde se encontram as mulheres do Acampamento Ilha Verde, bem como de outras realidades semelhantes, uma vez que o empoderamento é multidimensional.

\section{REFERÊNCIAS}

ALBERTI, Verena. Manual de história oral. 3. ed. Rio de Janeiro: Editora FGV, 2005.

ARAÚJO, Rubens Milagre. Uma retrospectiva da expansão do sistema na bacia do Rio Tocantins, com estudo de caso na região de Lajeado - Palmas - Porto Nacional (TO), 1996-2003. 2003. Orientador Arsênio Oswaldo Sevá Filho. Dissertação (Mestrado em Planejamento de Sistemas Energéticos) Universidade Estadual de Campinas, Campinas, SP, 2003. Disponível em: http://www.fem.unicamp. br/ seva/dissertMestr_RubensAraujo_03.pdf. Acesso em: 10 dez. 2018.

BRASIL. Relatório de Informações Sociais - Bolsa Família e Cadastro Único. 2017. Disponível em: https:// aplicacoes.mds.gov.br/sagi/Rlv3/geral/relatorio.php\#. Acesso em: 16 jan. 2018.
BRASIL. Manual do Sistema CadSUAS. Versão 2.0 Brasília: MDS, 2014a. Disponivel em: http://blog.mds. gov.br/redesuas/wp-content/uploads/2014/02/Manual-CadSUAS-v-2-0.pdf. Acesso em: 27 ago. 2014.

BRASIL. Ministério do Desenvolvimento Social e Combate à Fome. Avaliação de políticas públicas: reflexões acadêmicas sobre o desenvolvimento social e o combate à fome. Brasília: MDS; Secretaria de Avaliação e Gestão da Informação, 2014b. v. 1: Introdução e temas transversais.

BRASIL. Orientações técnicas sobre o PAIF: trabalho social com famílias do Serviço de Proteção e Atendimento Integral à Família - PAIF. Brasília: MDS, 2012. v. 2.

BRASIL. Comissão Intergestores Tripartite. Resolução n. 7, de 10 de setembro de 2009. Brasília: MDS, 2009. Disponível em: http://blog.mds.gov.br/redesuas/resolucao-no-7-de-10-de-setembro-de-2009/. Acesso em: 8 jul. 2019.

BRASIL. Decreto 5.209, de 17 de dezembro de 2004. Regulamenta a Lei n.10.836, de 9 de janeiro de 2004 que cria o Programa Bolsa Família, e dá outras providências. Brasília, 2004. Disponível em: http://www. planalto.gov.br/ccivil_03/_ato2004-2006/2004/decreto/d5209.htm. Acesso em: 5 jan. 2018.

BRISOLA, Elisa Maria Andrade; MARCONDES, Nilsen Aparecida Vieira. A história oral enquanto metodologia dentro do universo da pesquisa qualitativa: um foco a partir da análise por triangulação de métodos. Revista Ciências Humanas, Taubaté, SP, v. 4, n. 1, p. 124-36, jan./jul. 2011. Disponivel em: https://www. rchunitau.com.br/index.php/rch/article/view/9/8. Acesso em: 8 jul. 2019

CALAFATE, Jaqueline; PARENTE, Temis Gomes. O "instinto materno" como uma construção de gênero: discussões sobre o desejo de amamentar. 2014. Dissertação (Mestrado em Desenvolvimento Regional) Programa de Pós-Graduação em Desenvolvimento Regional, Universidade Federal do Tocantins, Palmas, 2014.

CAMPOS, André Gambier; CHAVES, José Valente. Seguro defeso: problemas enfrentados pelo programa. Mercado de Trabalho: Conjuntura e Análise (BMT), n. 56, fev. 2014. Disponível em: http://repositorio.ipea. gov.br/bitstream/11058/3782/1/bmt56_politicaemfoco03 seguro_defeso.pdf. Acesso em: 16 jan. 2018.

CECCHIN, Hareli Fernanda Garcia; PARENTE, Temis Gomes. O desempoderamento de mulheres beneficiárias do Programa Bolsa Família: questões de gênero no acampamento llha Verde - TO. 2016. Dissertação (Mestrado em Desenvolvimento Regional) - Programa de Pós-Graduação em Desenvolvimento Regional, (Mestrado em Desenvolvimento Regional) - Program
Universidade Federal do Tocantins, Palmas, 2016.

CELARIÉ, Nidia Hidalgo. Género, empoderamiento y microfinanzas: un estudio del caso en el norte de México. 2003. Tesis (Maestría)- Instituto Nacional de las Mujeres, México, 2003.

CNAS. Resolução n. 15, de 5 de junho de 2014. Brasília: Conselho Nacional de Assistência Social, 2014 Disponível em: http://www.mds.gov.br/cnas/legislacao/resolucoes/arquivos-2014/resolucoes-cnas-2014/. Acesso em: 20 maio 2015

FERREIRA, Amauri Carlos; GROSSI, Yonne de Souza. A narrativa na trama da subjetividade: perspectivas e desafios. Economia \& Gestão, Belo Horizonte, v. 2, n. 3, p. 120-34, jan./jun. 2002. Disponível em: http:// periodicos.pucminas.br/index.php/economiaegestao/article/view/112. Acesso em: 8 jul. 2019.

FIGUEIREDO, Gislayne Cristina; PINTO, José Marcelino de Rezende. Acampamento e assentamento: participação, experiência e vivência em dois momentos da luta pela terra. Psicologia \& Sociedade, Belo Horizonte, v. 26, n. 3, p. 562-71, 2014. Disponível em: http://www.scielo.br/scielo.php?pid=S010271822014000300005\&script=sci_abstract\&tIng=pt. Acesso em: 8 jul. 2019. 
FRAGA, Gerson Wasen. Memórias de terras e de águas: o Movimento dos Atingidos por Barragens (MAB) no norte do Rio Grande do Sul através da História Oral. In: SIMPOSIO NACIONAL DE HISTORIA, 27., 2013, Natal, RN. Anais [...]. ANPUH, 2013. Disponível em: http://www.snh2013.anpuh.org/resources/ anais/27/1371327960_ARQUIVO_memoriasdeterrasedeaguas2.pdf. Acesso em: 21 out. 2015.

FREITAS, Sônia Maria de. História oral: possibilidades e procedimentos. Eccos Revista Científica, São Paulo, v. 5 , n. 1, p. 175-87, jun. 2003

FREITAS, Ana Maria Lacerda de. Políticas públicas, gênero e autonomia econômica das mulheres: uma análise de Programas do governo brasileiro no período de 2000 a 2007. 2011. Dissertação (Mestrado em Desenvolvimento Social) - Universidade Estadual de Montes Claros, Montes Claros, MG, 2011

HORTA, José Luís Garcia; CARRILLO, María del Rosario Ayala; ZAPATA-MARTELO, Emma. ¿Empoderan las microfinanzas? Un estúdio de caso em Mexico. In: PARENTE, Temis Gomes; MIRANDA, Cynthia Mara (Org.). Arquiteturas de gênero: questões e debates. Palmas: UFT/EDUFT, 2015.

IBGE. Babaçulândia: histórico. Ferramenta Cidades, 2010. Disponível em: http://www.cidades.ibge.gov. $\mathrm{br} /$ painel/historico php?lang=\&codmun=170300\&search=tocantins $\mid$ babaculandia $\mid$ infograficos:-historico Acesso em: 8 abr. 2015.

MARIANO, Silvana Aparecida; CARLOTO, Cássia Maria. Gênero e combate à pobreza: Programa Bolsa Família. Revista Estudos Feministas, Florianópolis, v. 17, n. 3, p. 901-8, set./dez. 2009. Disponível em: http://wwW.scielo.br/scielo.php?script=sci_arttext\&pid=S0104-026X2009000300018\&lng=en\&nrm= so. Acesso em: 24 jul. 2014.

MOREIRA, Nathalia Carvalho et al. Empoderamento das mulheres beneficiárias do Programa Bolsa Família na percepcão dos agentes dos Centros de Referência de Assistência Social. Revista de Administração Pública, Rio de Jane php?pid=S0034-76122012000200004\&script=sci_arttext. Acesso em: 23 abr. 2015.

PARENTE, Temis Gomes. Gênero e (in)sustentabilidade de mulheres nos reassentamentos rurais da Usina Hidrelétrica de Estreito - Tocantins. OPSIS, Catalão, GO, v. 15, n. 2, p. 399-416, jul./dez. 2015. Disponível em: https://revistas.ufg.br/Opsis/article/view/33722. Acesso em: 8 jul. 2019.

PARENTE, Temis Gomes. Desenvolvimento regional na perspectiva de gênero. Projeto História, São Paulo, n. 45, p. 269-84, dez. 2012. Disponível em: http://revistas.pucsp.br/index.php/revph/article/ viewFile/15015/11209. Acesso em: 20 fev. 2015.

PARENTE, Temis Gomes, Gênero e memória de mulheres desterritorializadas. ArtCultura, Uberlândia, MG, v. 9, n. 14, p. 99-111, jan./jun. 2007. Disponivel em: http://www.seer.ufu.br/index.php/artcultura/ article/view/1451. Acesso em: 8 jul. 2019.

PARENTE, Temis Gomes; JUSTINO, Marcelo Lopes. (In)Sustentabilidade socioeconômica dos Reassentamentos Mariana e Oleircultures- Porto Nacional- TO-Brasil. REDES, Santa Cruz do Sul, RS, v. 18, n. 1, p. 108-31, jan./abr. 2013

PARENTE, Temis Gomes; GUERRERO, Olaya Fernández. O desempoderamento das mulheres dos reassentamentos rurais em Porto Nacional (TO, Brasil). História Oral, Rio de Janeiro, v. 2, n. 14, p. 173-97, jul./dez. 2011. Disponível em: http://www.revista.historiaoral.org.br/index.php?journal=rho\&page=artic le\&op=view\&path\%5B\%5D=237\&path\%5B\%5D=269. Acesso em: 8 jul. 2019.

PIZZIO, Alex; CECCHIN, Hareli Fernanda Garcia. O Movimento Interestadual das Quebradeiras de CocoBabaçu na região do Bico do Papagaio: reflexões sobre justiçasocial. Revista Brasileira de Desenvolvimento
Regional, Blumenau, SC, v. 3, n. 2, p. 111-33, 2015. Disponível em: http://proxy.furb.br/ojs/index.php/ rbdr/article/view/5443. Acesso em: 20 jan. 2018.

PORTELLI, Alessandro. Como se fosse uma história: versões do Vietnã - ensaios de história oral. São Paulo: Letra e Voz, 2010.

PORTELLI, Alessandro. História oral como gênero. Projeto História, São Paulo, v. 22, p. 9-36, jun. 2001 Disponivel em: http://revistas. pucsp. br/index.php/revph/article/view/10728/7960. Acesso em: 25 jan. 2018.

PORTELLI, Alessandro. O que faz a história oral diferente. Projeto História, São Paulo, v. 14, p. 25-39, fev. 1997. Disponível em: https://revistas.pucsp.br/index.php/revph/article/view/11233/8240. Acesso em: 20 jan. 2018

ROCHA, Teresa Hevia; CABA, Laura Peniche. Manual de elaboración de proyectos de sesarrollo social com perpectiva de gênero. 3. ed. México: Instituto Nacional de Lasmujeres, 2012.

SAFFIOTI, Heleieth lara Bongiovani. Ontogênese e filogênese do gênero: ordem patriarcal de gênero e a violência masculina contra mulheres. FLACSO-Brasil, Série Estudos e Ensaios, Ciências Sociais, jun. 2009. Disponivel em: http://flacso redelivre org br/files/2015/03/Heleieth Saffioti.pdf. Acesso em: 8 jun. 2019.

SILVA JÚNIOR, Cícero Pereira da. Memória, dádiva e distopia: impactos socioambientais da UHE Estreito sobre a llha de São José - TO. 2014. Dissertação (Mestrado em Linguagens e Saberes na Amazônia) Universidade Federal do Pará, Bragança, 2014.

SILVA, Valdir Pierote; BARROS, Denise Dias. Método história oral de vida: contribuições para a pesquisa qualitativa em terapia ocupacional. Revista de Terapia Ocupacional da Universidade de São Paulo, São Paulo, v. 21, n. 1, p. 68-73, jan./abr. 2010. Disponível em: http://www.revistas.usp.br/rto/article/view/14087 Acesso em: 25 maio 2018

THOMPSON, Paul. A voz do passado: história oral. Tradução Lólio Lourenço de Oliveira. 3. ed. Rio de Janeiro: Paz e Terra, 2002.

TRIERWEILER, Roberta Rodrigues; MEDEIROS, Mara Rosange Acosta. As mulheres e o Bolsa Família: um estudo no Loteamento Dunas em Pelotas, RS. In. SEMINÁRIO DE SERVICO SOCIAL, TRABALHO E POLÍTICA SOCIAL, 2015, Florianopolis. Anais... Florianopolis: UFSC, 2015. Dispo seminarioservicosocial2017.ufsc.br/files/2017/05/Eixo_3_113.pdf. Acesso em: 21 maio 2018.

ZAPATA-MARTELO, Emma et al. Microfinanciamiento y empoderamiento de mujeres rurales - las cajas de ahorro y crédito en México. 1. reimp. México: Plaza y Valdés, 2008.

ZAPATA-MARTELO, Emma et al. Microfinanciamiento y empoderamiento. México: Plaza y Valdés, 2004.

\section{Sobre os autores:}

Hareli Fernanda Garcia Cecchin - Mestrado em Desenvolvimento Regional pela Universidade Federal do Tocantins (UFT). Graduação em Psicologia pelo Centro Universitário Luterano de Palmas, TO. Psicóloga da UFT. E-mail: harelifernanda@gmail.com, Orcid http://orcid.org/0000-0003-4875-7638

Temis Gomes Parente - Pós-Doutorado pelo CEDEPLAR/UFMG. Doutorado e mestrado e m História pela Universidade Federal de Pernambuco (UFPE). Graduação em História pela Universidade Federal do Piauí (UFPI). Professora Associada IV da Universidade Federal do Tocantins (UFT). E-mail: temis@mail.uft.edu.br, Orcid: http://orcid.org/0000-0001-6086-6402 
